\title{
Interpersonal Relations: Psychological Violence and the Student's Status in the Academic Group
}

\author{
Kozhukhar Galina Socratovna*
}

Faculty of Social Psychology, Moscow State University of Psychology and Education, Moscow, Russia

Received: May 01, 2014; Accepted: June 04, 2014; Published: June 06, 2014

*Corresponding author: Kozhukhar Galina Socratovna, Faculty of Social Psychology, Moscow State University of Psychology and Education, Moscow, Russia, Fax: $011+7$ (495) 632-95-44; Email: gsk04@mail.ru

\begin{abstract}
The main questions of this article were: are the different kinds of psychological violence the predictors of student's statuses and which type of this influence we can find? The answer to these questions is an important symptom of intragroup psychological health because links between violence and statuses demonstrated relation's quality. There were investigated such kinds of psychological violence as communicative intolerance, cynicism, aggression, hostility. We required finding the influence of these personality traits on intragroup relations and informal power, sociometric and referentometric student's statuses. The sample consisted of 204 university psychology students of the first, the third and the fifth years. Data were collected via Sociometric (Moreno) and Referentometric (Chedrina) procedures, Power structure (Kondratiev), Questionnaire of Communicative Tolerance (Boyko) and the Cook - Medley hostility scale. According to the results of descriptive statistics the level of some investigated characteristics of psychological violence was within the mean significance. But the mean significance of communicative intolerance was more than the tendency to the communicative tolerance. All characteristics of psychological violence (intolerance, cynicism, aggression, hostility) had direct significant correlations between each other and these factors had inverse significant links with different types of statuses. Therefore we concluded that cynicism, aggression and hostility weren't predictors of any student's statuses in the educational group. At the same time aggression and hostility were mediators for communicative intolerance as statuses predictors lowering every kind of statuses.
\end{abstract}

Keywords: Psychological violence; Intolerance; Cynicism; Aggression; Hostility; Intra-group status

\section{Introduction}

One of the basic statements of modern educational psychology asserts that the effectiveness of educational process depends on the level of psychological safety of educational environment [1-8]. In its turn psychological safety reflects the quality of interpersonal relations between the participants of educational environment. So it is the safety of communication and relations in different types of educational institutions that can be considered the key element and system-making characteristic of the whole safety of their educational environment.

The fundamental role of communication as the main condition of educational environment safety is determined by many factors. Thus, according to the theory of I. Bayeva and her colleagues, basic characteristics of educational environment safety are independence from psychological violence in interaction and the possibility to satisfy the need in personally trustful communication which influences referential importance of communicative space [1-3].

In Russian psychology the understanding of psychological safety of the educational environment is based on definition by $[1,9]$. This definition includes three basic components: the referential importance of educational environment, possibility to satisfy basic needs in personal trustful communication, providing of participants security from psychological violence in interactions between all participants of the educational process.

Dialogical communicative space characterized by the absence of psychological violence will create the environment of "ontological safety instead of existential anxiety" Shyu [10], providing productive development and self-development of a person. Many investigations showed the negative effect of violent acts and of the violence environment on the academic performance levels of the students, their mental health and health [11-14].

The psychological core of ontological safety makes the complete emotional and cognitive feeling of "basal trust» which allows a person to find the meaningfulness of life [15]. According to E. Ericson's classical definition, the basal trust means such a person's set to him/herself and the world which includes the person's trust to him/herself and the feeling of indispensable propensity of other people to him/her [16].

Psychological safety of educational environment represents a complicated phenomenon which is connected with many characteristics and depends on different factors. One of the basic indicators of educational environment's safety, as it was said above, is the quality of interpersonal relations between the participants of educational environment.

Nowadays there are various definitions of psychological safety, but the majority of them single out threats in the form of psychological violence as the primary factor destroying safety $[1,2,4]$. 
The terms "danger", "risk", "threat" are traditionally included into the conceptual base of psychology of safety. In psychological dictionaries the term "threat" is explained as intention to harm other person in any form, i.e. as a type of psychological violence.

Psychological violence acts as a fundamental obstacle on the way to establishing personally confidential relations between the members of academic groups which makes it impossible to create dialogical environment favorable for their development $[1,2]$. Psychological violence in interpersonal interaction can be shown in various forms: destructive criticism, accusations, insults, opened and veiled threats, emotional pressure, etc.

So the major criterion of psychological safety of educational environment is a low level of psychological violence $[6,7]$. Psychologically healthy and safe intragroup relations favorable for training and personal development are based on a low level of violence manifestation and the ability to transform negative intentions into positive behavioral forms. And leaders and high status members of community play the leading role in management and regulation of intragroup interactions.

The main question of the given research is whether characteristics of psychological violence in intergroup relations are predictors of the student's status in the academic group and if so, what character this influence has. The answer to this question is connected with understanding the quality of relations in student's groups in the context of social role interaction, as director reverse correlation of psychological violence with intragroup student's status in interpersonal communication is an indicator of danger or safety of educational environment.

In the given work we examine such characteristics of psychological violence as communicative intolerance, cynicism, aggression and hostility as predictors of the student's status in the academic group. We are interested in three types of status: sociometric, referentiometric and the one of informal power. These types of status indicate relations of interpersonal importance. Hence, revealing correlations between psychological violence and intragroup status, we answer the question whether significant relations between students can mean violent ways of their implementation among students-psychologists.

\section{Methods}

\section{Sample}

The sample consisted of 204 first, third and fifth year students-psychologists of one of the universities in Moscow aged from 17.5 till 23.4 years; 157 females (78\%) and 47 males (22\%). All the students came from in socially safe families. The data were collected by I. Vagurin and G. Kozhuhar).

\section{Measures}

Characteristics of psychological violence were investigated via Boyko's questionnaire of communicative tolerance (whose questions, as a matter of fact, are directed to revealing intolerance) Boyko [17] and the Cook - Medley hostility scale Labunskaya [18].
Communicative Tolerance Scale [17] consisted of 45 judgments which were evaluated with Likert scale from 0 (strongly disagree) till 3 (strongly agree). Indices for 9 subscales and the general index of communicative tolerance were found. In the study we used only the general index of communicative tolerance/intolerance. The maximum number of points (135) testifies absolute intolerance to other people. The minimum number of points (0) displays tolerance to all types of partners in all situations. On the average, according to the data received by Boiko, heads of medical institutions and divisions had 40 points, nurses -43 points, tutors -31 points. The general index is interpreted as tolerance tendency if it is less than 40 points and is testified as intolerance tendency when it is more than 40 points. Cronbach's $\alpha$ (alpha) as a coefficient of internal consistency of the integral index of tolerance/intolerance was equal 0.855 .

The Cook-Medley Hostility Scale (Russian version) contains 27 statements. Items were administered with a 6-point Likert scale ( 6 = always, $1=$ never). Levels of these three subscales (hostility (5 items), cynicism (13 items) and aggression (9)) were counted by means of the key applied to this scale. Interpretation of the results for a cynicism scale is as follows: 65 points and more is a high indicator; $40-65$ points is an average index with a tendency to high; 25-40 points is an average index with a tendency to low; 25 points and less is a low indicator. Interpretation of the results for an aggression scale is as follows: 45 points and more make a high indicator; $30-45$ points make an average index with a tendency to high; $15-30$ points make an average index with a tendency to low; 15 points and less make a low indicator. Interpretation of the results for animosities scale is as follows: 25 points and more is a high indicator; $18-25$ points is an average index with a tendency to high; $10-18$ points is an average index with a tendency to low; 10 points and are less is a low indicator.On a cynicism scale Cronbach's alpha was equal 0.556; for aggression Alpha $=0.748$ and for hostility Alpha $=0.789$.

To define intragroup individual status we used the procedures revealing interpersonal relations in group, such as sociometry (Moreno, Russian version), referentometry (Chedrina), and informal intragroup power structure evaluation (Kondratiev) [19].

\section{Sociometry}

We used a sociometric method to define interpersonal relationships in an academic group. We asked three questions with 3-answer choices limited: "With whom you would like to conduct scientific research together?" (The business criterion); "With whom you would like to live in the same tent in a camp?" (The emotional criterion); "With whom you would like to continue your education in a new group if your group is going to be reformed?" (The mixed criterion). The received data were used for studying business status, emotional, mixed and sociometric status. The sociometric status was counted up as average mean of the business, emotional and mixed status in academic group for each student. At the analysis of the data the mixed criterion was not considered. 


\section{Referentometry}

Depending on a research goal, while carrying out a referentometric procedure firstly it is necessary to define a set of opinions and judgments of all the members of the group without an exception concerning some object of estimation most significant for them. As the objective of applying this method in the study was to find out students with the highest referential status in an academic group, at the first stage of the study the sociometric method was used. At the second stage of the research the respondents had to choose no more than three fellow students, whose filled-in sociometry forms were of the greatest interest for them and to write down their names in a ranked list column in order of preference. At data processing only the results of the second stage, i.e. referentometric choices, were analyzed. Calculation was just the same as at sociometric results processing.

The procedure of informal intragroup power structure evaluation (in contact community).

This procedure is based on the fact that people make choices in interpersonal relations due to power of influence of the perceived person on the perceiving personality. So the applied techniquepresupposes ranging group members according to the power of their influence. The students receive formtables with the list of examinees' surnames on the left. On the right the participants are to put down the number of the place which they attribute to each person in the group due his/her powerful influence. Then the data is averaged, and each examinee receives a certain rank on the basis of an average index in the academic group.

\section{Results and discussion}

According to the results of descriptive statistics the level of such characteristics of psychological violence as cynicism (M $=47.82 ; 61.8 \%$ of students), aggression ( $\mathrm{M}=31.48 ; 58.3 \%$ of students) and hostility ( $M=19.69 ; 65.6 \%$ of students) was within mean significance. Though according to the standard levels in the Russian version of the scale the mean scores of the three scales appeared at the average level with a tendency to high, we interpreted results at the average level, because the following level was designated as average with a tendency to low. So we considered all the mean students' results as lying within the average range.

The level of hostility at students-psychologists appeared a little above the levels of cynicism and aggression. Though the indicators are within mean significance, we believe, that for psychologists it is more productive to have these parameters on a medium level with the tendency to a low one or on a low level.

The expected value of communicative tolerance made 48.03 points. According to Boyko, the average index of communicative tolerance at nursesis 43 points, at doctors - 40 points, at kindergarten teachers - 31 points [17]. The lower it is, the better tolerance is expressed. Maximum intolerance can theoretically reach 135 points. In comparison with representatives of helping professions (nurses, doctors, teachers), it is possible to say that students' expected value of communicative tolerance is on the edge between tolerance and intolerance.
Tolerance or intolerance makes the major quality characteristic of interpersonal relations. According to A. Asmolov, tolerance assumes willingness to accept other people as they are, and to co-operate with them on the basis of consent, reciprocity and active stand manifestation of all the parts concerned. Tolerance is one of the basic components of life philosophy of a mature person. Being its value, it becomes evident in the respect for the views and values of other people [20].

Within the limits of the socialpsychological approach, tolerance is understood as a set, attitude, need, value, norm, point of view, belief. Besides, it is a certain moral and legal category whose genesis is influenced by the society [21].

If intolerance prevails in intragroup relations of educational community, there will be difficulties in confirming the status connected with productive pro-social activity of group members. In other words, within the group structure tolerance can be examined as one of the basic system-making factors of status positions of group membership.

According to the results of Pearson's correlation analysis, all characteristics of psychological violence have direct significant correlations between each other Table 1 .

All characteristics of psychological violence have inverse significant links with three types of student's status as well as with business and emotional status as substantial criteria of sociometric position. In other words, if the tendency to apply psychological violence increases in students' community, those students who use it will lower their status and interpersonal importance for the majority of group members Table 2 .

Violence prophylactic treatment among children and teenagers is the major condition of psychological violence prevention both in students' community and in the society as a whole. It is experimentally proved, that such expressions of psychological violence as prosecution, intimidation and victimization in school days, with high degree of probability, lead to aggression and violence in advanced age, determining the existence of general long-term antisocial orientations [22].

Hence, the investigated characteristics of psychological violence are connected in such a way that an increase of one of them will cause a rise of all the others as we have found correlations between all of them.

The results of the regressive analysis (the linear plural analysis, a step-by-step method) reveal, that communicative tolerance is a predictor of all types of student's status: the lower level of intolerance (or the higher level of tolerance) the student demonstrates in communication, the higher any of student's status in the academic group is Table 3, Figure 1 . At the same time, aggression and hostility do not have direct links with any of the status. Thus, aggression and hostility can be mediators for lowering every type of status, as they have complex influence on communicative intolerance which is considered the main predictor decreasing intragroup position of the student.

By the results of factorial analysis Table 4, all of them are included in one and the same factor which confirms the integrity 
Table 1: Correlations between the characteristics of psychological

\begin{tabular}{|c|c|c|c|}
\hline & Cynicism & Aggression & Hostility \\
\hline Communicative intolerance & $0.383^{* *}$ & $0.456^{* *}$ & $0.481^{* *}$ \\
\hline Cynicism & & $0.565^{* *}$ & $0.625^{* *}$ \\
\hline Aggression & & & $0.592^{* *}$ \\
\hline
\end{tabular}

violence.

Table 2: Correlation of psychological violence characteristics with different kinds of the student' status in the academic group.

\begin{tabular}{|c|c|c|c|c|c|}
\hline & Referetometric status & Sociometric status & Business status & Emotional status & Informal power \\
\hline Communicative intolerance & $-0.325^{* *}$ & $-0.422^{* *}$ & $-0.384^{* *}$ & $-0.430^{* *}$ & $-0.538^{* *}$ \\
\hline Cynicism & $-0.195^{* *}$ & $-0.262^{* *}$ & $-0.244^{* *}$ & $-0.223^{* *}$ & $-0.212^{* *}$ \\
\hline Aggression & $-0.212^{* *}$ & $-0.247^{* *}$ & $-0.218^{* *}$ & $-0.267^{* *}$ & $-0.314^{* *}$ \\
\hline Hostility & $-0.214^{* *}$ & $-0.248^{* *}$ & $-0.252^{* *}$ & $-0.271^{* *}$ & $-0.293^{* *}$ \\
\hline
\end{tabular}

${ }^{* *}-\mathrm{p}<0.01$

Table 3: The results of the regressive analysis.

\begin{tabular}{|c|c|c|c|c|c|}
\hline \multicolumn{6}{|c|}{ Predictor: communicative intolerance } \\
\hline Dependent variables & Sum of squares & $\mathbf{F}$ & \multicolumn{2}{|c|}{ Standardized CoefficientsBeta } & Sig. \\
\hline Sociometric status & 20.540 & 43.792 & \multicolumn{2}{|c|}{-0.422} & 0.000 \\
\hline Business status & 15.090 & 34.846 & \multicolumn{2}{|c|}{-0.384} & 0.000 \\
\hline Emotional status & 18.555 & 45.730 & \multicolumn{2}{|c|}{-0.430} & 0.000 \\
\hline Referetometric status & 14.417 & 23.812 & \multicolumn{2}{|c|}{-0.325} & 0.000 \\
\hline Informal power & 2131.701 & 82.289 & \multicolumn{2}{|c|}{-0.538} & 0.000 \\
\hline \multicolumn{6}{|c|}{ Predictors: aggression and hostility } \\
\hline \multirow{2}{*}{$\begin{array}{c}\text { Communicative } \\
\text { intolerance }\end{array}$} & \multirow{2}{*}{14548.070} & \multirow{2}{*}{38.402} & Hostility & 0.325 & 0.000 \\
\hline & & & Aggression & 0.263 & 0.001 \\
\hline \multirow{2}{*}{ Cynicism } & \multirow{2}{*}{8981.733} & \multirow{2}{*}{82.041} & Hostility & 0.448 & 0.000 \\
\hline & & & Aggression & 0.300 & 0.000 \\
\hline
\end{tabular}

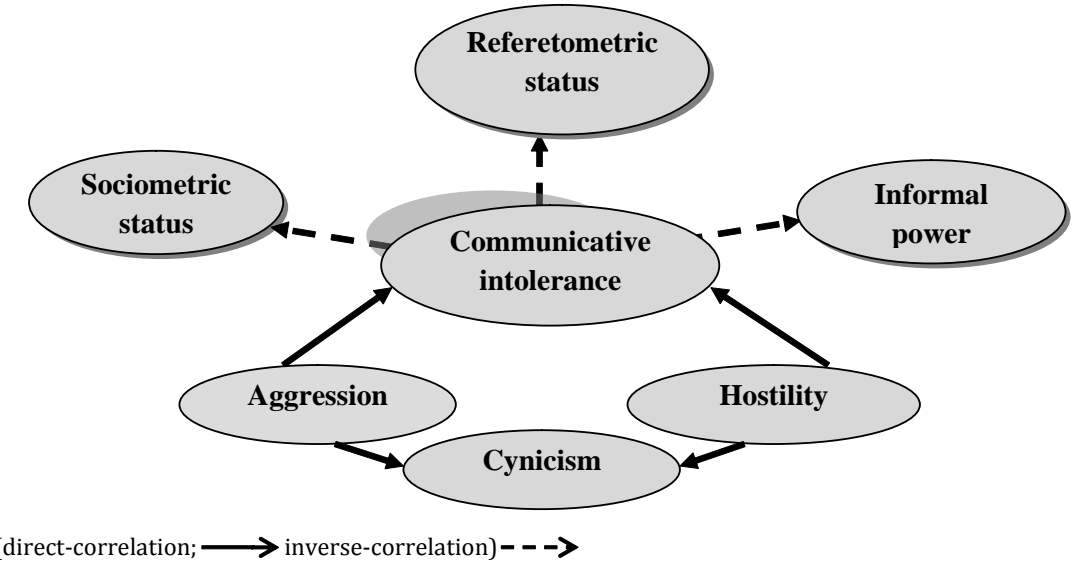

Figure 1: Characteristics of psychological violence as predictors of student's status in group .

of existence and functioning of the phenomenon of violence/ non-violence at students of our sample. Different kinds of status make a separate factor, that as we believe, confirms, that they can be examined through the integrated status of the student in the group, illustrating the degree of his/her interpersonal importance in contact community [19].

In many researches hostility is considered the major indicator of psychological violence. Hostility represents an extensional phenomenon which is integrated and complex and contains cognitive, emotional and behavioral aspects of person's negative orientation towards interpersonal interaction with other people. Hostility includes cynicism, anger, irritability, mistrust and aggression. Its most general components are cynicism (belief that others are primarily motivated by selfish interests) and mistrust 
Table 4: Results of factor analysis ofpsychological violence characteristics and different types of student's status.

\begin{tabular}{|c|c|c|}
\hline \multicolumn{3}{|c|}{ Rotated Component Matrix } \\
\hline & \multicolumn{2}{|c|}{ Component } \\
\hline & 1 & 2 \\
\hline Business status & 0.872 & \\
\hline Referentometric status & 0.789 & \\
\hline Sociometric status & 0.767 & \\
\hline Emotional status & 0.743 & \\
\hline Informal power & 0.533 & \\
\hline Hostility & & 0.844 \\
\hline Aggression & & 0.818 \\
\hline Cynicism & & 0.811 \\
\hline Communicative intolerance & -0.477 & 0.582 \\
\hline Extraction Method: Principal Component Analysis. & & \\
\hline Rotation Method: Varimax with Kaiser Normalization. & & \\
\hline Rotation converged in 3 iterations. & & \\
\hline & & \\
\hline
\end{tabular}

(expectation that people, with high probability, are sources of harm and bad treatment). These features define a hostile style of interpersonal interaction which is characterized by the existence of problems, avoidance behavior, easily appearing irritation. Hostility is a cognitive construct, unlike aggression which is understood as behavior and emotions of anger [23-25]. T. Smith defines hostility as devaluation of other people's values and motives, expectation that other people are probable sources of offences, opposition in relation to others, and desire to harm or perception of harm from others [26]. In many researches correlation of hostility with bad health is proved. In particular, cynical hostility as a component of general hostility is considered a psychosocial factor of poor health, raising susceptibility to illnesses, medical dysfunction and risk of death [27]. In turn, chronic hostility bring sunfavorable consequences to health, including hypertension, ischemic heart disease and death [2831].

Cynical hostility contributes to increased cardiovascular risk in women and cynicism may especially be detrimental to younger women [32]. Some results obtained from a sample of young adults showed that Cook-Medley hostility (Ho) scores were significantly associated with life stress, trait anger, loneliness and irrational beliefs [29]. Many investigations show that anger and hostility are connected with future coronary heart disease (CHD) and outcome both in healthy and CHD people [33].

These facts underline necessity and importance of the practice of psychological management focused on hostility in the prevention and treatment of psychosomatic diseases of the students.

Thus, quality of relations in students' groups is directly connected not only with the students' psychological state, but with their future physical health as well.

Analyzing the received data by means of plural regressive analysis doesn't allow including cynicism into the prediction model of types of status and communicative intolerance. At the same time, the linear analysis by the method of compulsory inclusion shows that cynicism predicts the level of communicative intolerance.

Interesting it may be that if a person possesses hierarchical or formal power as well as the power connected with incomes, this power generates doubts concerning honesty of other people. As a result, cynical thoughts about the partners' intentions in communication build a barrier to healthy relations [34]. But in this study the informal power of students based on the authority of personality, but not on his/her formal position was investigated. Probably for this reason our results showed inverse correlations: the higher the student's status is in hierarchies of power, the more intensive his/her authoritative influence is, the lesser degree of psychological violence she/he is inclined to use, and the lesser typical of him/her are cynicism, aggression and hostility.

For our investigation it was very important that in many researches influence of a peer status in the school class on the consequences of child's long-term development was shown. In more details, lower peer status was connected to a declined possibility of getting higher levels of education (to both upper secondary school and to tertiary education) and raised threats of adult unemployment [35]. Also, other studies found out an association between low peer status and a broad range of diseases such as mental health problems [36,37].

The results of our research received on sample of studentspsychologists did not coincide with the results indicated that youth nominated as aggressive had high status positions within peer groupsand were more central members of their peer group[38-40].

Thus, our results have shown that the interrelation of displays of psychological violence and different kinds of the status in student's groups has its own specificity.

\section{Limitations}

There were clearly some limitations to this study that must be noted. Our data was collected using only students-report measures. Although these methods gave the valid results, they do not capture social dynamics. Additional research should incorporate observational methods as well as informant reports from professors or students from others academic groups. In this research we have not conducted the comparative analysis of features of psychological violence at students with the different status in their academic group (low, average, high status). Also we have not revealed specificity of association of psychological violence characteristics and the status depending on a study year in the university (1-st, 3-rd and 5-th course), and besides gender features have not been considered.

\section{Conclusions and suggestions for future research}

The results of correlation and factor analysis show that all investigated characteristics of psychological violence in interpersonal relations have direct significant correlations between each other, while regressive analysis reveals 
peculiarities of the influence of given indicators on each other. We consider there is an interconnected complete complex of characteristics of psychological violence whose weak expression provides the student with high status.

Figure 1 illustrates inverse links between communicative intolerance and status. Aggression and hostility are depicted as the predictors of intolerance and cynicism (they are included into the same model), cynicism directly increases intolerance, and these three factors appear to be mediators of lowering any type of status by intensifying intolerant tendencies.

The results of the study lead us to several conclusions. Firstly, psychological violence in student groups lowers the status of those students who apply it. Secondly, the level of manifestation of psychological violence in student groups helps to predict the individual status of each student as well as the peculiarities of different status strata as marked levels of intragroup hierarchy. Thirdly, the main predictor of lowering student psychologists' status in contact community appears communicative intolerance whose level of manifestation is directly correlated with aggression, hostility and cynicism. Fourthly, psychological violence is an integral phenomenon in which changing of any characteristic consequences in changing all the other parameters and the phenomenon as a whole.

Given the serious consequences for personal and professional students' development related to psychological violence and ingroup status, future research should examine how the results of this and similar studies are connected to well-being and various characteristics of psychological health and how it will provide a better contextual understanding of these phenomena to improve social and professional competence of the students.

The importance of studying psychological violence in educational environment lies in the fact that the degree of its manifestation in intragroup relations becomes a health predictor of educational process participants and their academic achievements. Health is considered to be a complex phenomenon which includes the analysis of consequences of educational process influence on person's physical, mental, psychological and sociopsychological status in the society.

\section{References}

1. Baeva IA (2002) Psychological safety in education: the Monography. The Union, $\mathrm{SPb}$.

2. Baeva IA, Volkova EN, Laktionova EB (2009) Psychological safety of educational environment: the Manual. In: Baevoj IA (Ed.). The Ekoninform. Moscow, Russia.

3. Velichko EV (2011) Managing psychological safety of college educational environment. Psychology in Russia and abroad: materials international conference. Renome, SPb. 72-75.

4. Grachev GV (1998) Informational and psychological safety of a person: a set state and possibilities of psychological defense. Publishing house RAGS.

5. Ivanova VI (2007) Experimental research of the significance of psychological safety of educational environment in the system of multilevel professional training. The World of psychology 3: 98-110.
6. Rassoha NG (2005) Representation of psychological safety of school educational environment and types of interpersonal relations of its participants: Dissertation of the candidate of the Psychol. Sciences. $\mathrm{SPb}$.

7. Rubtsov VV,Baeva IA (2008) Psychological safety of the educational environment as a condition of psychosocial well-being of a schoolchild. Safety of the educational environment: the Collection of articles. In: Kodzhaspirova GM (Ed.). The Ekon-inform, Moscow, Russia, pp. 4-10.

8. Symanuk EE (2005) Psychological safety of educational environment. Ural ГУ, Perm, Russia.

9. Baeva IA (2006) Obespecheniepsihologicheskojbezopasnosti v obrazovatelnomuchrezhdenii. Rech, SPb.

10. Shyu M (2002) The Essential Conditions for Reflective Learning Based on Ontological Security. Bulletin of Adult and Continuing Education 31: 185206.

11. Krug EG, Dahlberg LL, Mercy JA, Zwi AB, Lozano R (Orgs.) (2002) World report on violence and health. World Health Organization, Geneva.

12. Rothon C, Head J, Klineberg E, Stansfeld S (2011) Can Social Support Protect Bullied Adolescents from Adverse Outcomes? A Prospective Study on the Effects of Bullying on the Educational Achievement and Mental Health of Adolescents at Secondary Schools in East London. J Adolesc 34 (3): 579-588.

13. Strøm IF, Thoresen S, Wentzel Larsen T, Dyb G (2013) Violence bullying and academic achievement: A study of 15-year-old adolescents and their school environment. Child Abuse Negl 37(4): 243-251.

14. Vaillancourt T, McDougall P (2013) The link between childhood exposure to violence and academic achievement: complex pathways. J Abnorm Child Psychol 41(8): 1177-1178.

15. Giddens A (1991) Modernity and Self-Identity: Self and Society in the Late Modern Age. Stanford University Press, Stanford, CA, USA.

16. Ericson E (1996) Identity: youth and crisis. In Erik h Erikson (Ed.), WW Norton Company, New York, Usa, pp.15-295.

17. Boyko VV (2004) The energy of emotions. Peter, SPb.

18. Labunskaya VA, Breus ED, Mendzheritskaya JUA (2001) Psychology of difficult communication: Theory Methods Diagnostics Correction. Academy.

19. Kondratyev MJU, Ilyin VA (2007) The ABS of a social psychologistexpert. PER SE.

20. Asmolov AG (1998) Tolerance in public consciousness of Russia. ИЭАРАЮ.

21. Bardier GL (2005) Social psychology of tolerance. St. Petersburg State University, $\mathrm{SPb}$.

22. Ttofi M, Farrington D, Lösel F (2012) School bullying as a predictor of violence later in life: A systematic review and meta-analysis of prospective longitudinal studies. Aggression and Violent Behavior 17(5): 405-418.

23. Eckhardt C, Norlander B, Deffenbacher J (2004) The assessment of anger and hostility: a critical review. Aggression and Violent Behavior 9 (1): 17 43.

24. Miller TQ, Smith TW, Turner CW, Guijarro ML, Hallet AJ (1996) A metaanalytic review of research on hostility and physical health. Psychol Bull 119(2): 322-348

25. Powell LH, Williams K (2007) Hostility Encyclopedia of Stress. In Fink MG (Ed.), Academic Press, New York, USA, pp. 354-358. 
26. Smith TW (1994) Concepts and methods in the study of anger hostility and health. In Siegman AW, Smith W Timothy (Ed.), Anger hostility and the heart. Lawrence Erlbaum Associates, Hillsdale, NJ, USA, pp. 23-42.

27. Strong D, Kahler C, Roger L, Greene R, Schinka J (2005) Isolating a primary dimension within the Cook - Medley hostility scale: a Rasch analysis. Personality and Individual Differences 39(1): 21-33.

28. Chatkoff D, Maier K, Javaid J, Hammoud M, Munkrishna P (2009) Dispositional hostility and gender differentially relate to cognitive appraisal engagement and cardiovascular reactivity across cognitive and emotional laboratory tasks. Personality and Individual Differences 47(2): 122-126.

29. Hart K, Hope C (2004) Cynical hostility and psychosocial vulnerability model of disease risk: confounding effects of neuroticism (negative affectivity) bias. Personality and Individual Differences 36(7): 1571-1582.

30. Newman JD, Davidson KW, Shaffer JA, Schwartz JE, Chaplin W, et.al (2011) Observed Hostility and the Risk of Incident Ischemic Heart Disease: A Prospective Population Study From the 1995 Canadian Nova Scotia Health Survey. J Am Coll Cardiol 58(12): 1222-1228.

31. Smith TW, Sanders JD, Alexander JF (1990) What does the Cook and Medley hostility scale measure? Affect behavior and attributions in the marital context. J Pers Soc Psychol 58(4): 699-708.

32. Demarble JB, Moskowitz DS, Tardif JC, D'Antono B (2014) The relation between hostility and concurrent levels of inflammation is sex, age and measure dependent. J Psychosom Res 76(5): 384-393.

33. Chida Y, Steptoe A (2009) The Association of Anger and Hostility With
Future Coronary Heart Disease: A Meta-Analytic Review of Prospective Evidence. J Am Coll Cardiol 53(11): 936-946.

34. Inesi M, Gruenfeld D, Galinsky A (2012) How power corrupts relationships: Cynical attributions for others generous acts. Journal of Experimental Social Psychology 48(4): 795-803.

35. Almquist Y, Modin B, Östberg V (2010) Childhood social status in society and school: Implications for the transition to higher levels of education. British Journal of Sociology of Education 31(1): 31-46.

36. Modin B, Östberg V, Almquist Y (2011) Childhood peer status and adult susceptibility to anxiety and depression. A 30-year follow-up of Stockholm girls. J Abnorm Child Psychol 39(2): 187-199.

37. Almquist YB, Brännström L (2014) Childhood peer status and the clustering of social economic and health-related circumstances in adulthood. Soc Sci Med 105: 67-75.

38. Estell DB, Farmer TW, Pearl R, Van Acker R, Rodkin PC (2008) Social status and aggressive and disruptive behavior in girls: individual group and classroom influences. J Sch Psychol 46: 193-212.

39. Farmer TW, Xie H, Cairns BD, Hutchins BC (2007) Social synchrony peer networks and aggression in school. In Hawley PH, Little TD, \& Rodkin PC (Eds.), Aggression and adaption: The bright side to bad behavior. Erlbaum, New York, USA, pp.209-234

40. Hoff KE, ReeseWeber M, Schneider WJ, Stagg JW (2009) The association between high status positions and aggressive behavior in early adolescence. Journal of School Psychology 47: 395-426. 